\title{
REMOTE LEARNING IN THE CONTEXT OF SCHOOL EDUCATION: CHALLENGES AND OPPORTUNITIES
}

\author{
Manoj Kumar Dash \\ Regional Director, IGNOU Regional Evaluation Center, Bhubaneswar, Odisha, India \\ Email: drdash@ignou.ac.in
}

How to cite this paper:

Dash, Manoj Kumar (2021)

Remote Learning in The

Context of School

Education: Challenges and

Opportunities, Journal of

Global Resources, Vol. 07 (02)

DOI:

10.46587/JGR.2021.v07i02.018

Received: 18 April 2021

Reviewed: 11 May 2021

Revised: 05 June 2021

Final Accepted: 16 June 2021

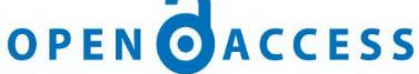

Freely available Online www.isdesr.org
Abstract: The COVID-19 pandemic brought a revolution in teaching learning process at all levels of education. School education is not an exception to it. Its impact found all around in varieties of ways. Educational institutions, teachers, teacher educators responded to this situation actively which ultimately forced the students and parents make a transition from conventional mode of classroom teaching learning process to online mode of remote teaching-learning process. A virtual learning environment is created for the students to manage the situation, as there were no other options available. The present piece of work is an attempt to assess the situation of online education (teaching and learning practices at a distance) at school level in Odisha. The findings of the study reflect a comprehensive view of various stakeholders (teachers, students and parents) associated with education of children at school levels and the need for an effective and efficient pedagogy for online education. It also established the fact to strengthen the resources required for making the online teaching learning process effective from the point of view of all stakeholders. The findings of the study also revealed how and why integration of technology (blending) is essential for capacity building of teachers and to support teaching-learning in the context of school education in Odisha. Also, the implications of this study are of very important for designing, development and implementation of online education for quality improvement in school education sustainably.

Keywords: Online Education, Integration of Technology, Teaching-Learning Process 


\section{Introduction}

With the spread of corona virus schools, colleges, universities all around the globe are closed. Millions of students are locked in homes. There are no other options other than online virtual mode including schools in our country as well. Now everybody is looking for creating a network of online resources and infrastructure. Every school is working with their management, head teacher, teachers and parents to interact with their children. The question before the teaching community was "how to continue teaching-learning process at a distance? Quality instruction (teaching-learning) is very important for overall cognitive and affective development of students. The need of the hour is to have a complete and comprehensive digital infrastructure to ensure effective learning students at a distance in the context of school education. With closure of schools across the country institutions and individuals are exploring alternative possible ways to provide education to students using ICTs such as Internet, TV, and radio. However, access to ICTs technologies is limited and a distant dream for many in our county especially among poor households, rural \& remote places. All educational institutions and individuals are making experiments with various elearning tools and platforms to deliver content online effectively. Importance is on active learning approaches with appropriate instructional design to deliver the content online. Many of the institutions are now able to manage to certain extent to provide quality inputs online to our students and many are also still finding a way to make use of the platform effectively. India, with more than 260 million students each year is the largest in the world in the school system. It's a new experience for the teachers to teach at a distance, understand the concept of remote teaching-learning, communicate with students in real-time, make use of a variety of e-resources, assign them to individual and/or facilitate collaborative work, assess learners' understanding, making formative and summative assessments, provide feedback to individual students for further improvement etc. The present study comprehensively covers all aspects to understand the whole and suggest a road map to make this initiative a great model of sustainable development in teaching learning process. COVID-19 has shown a huge gap in digital divide among our students. In order to learn online via these Platforms, a student would need to have access to the platform and guidance from parents. In terms of access, the prerequisite to learn via the online platform would be to have internet and a device such as computer, laptop, tablet or smartphone. In urban areas, there are complaints that children have to share devices and they could not fully utilize the lessons online due to slow internet connections or lack of devices. However, in rural and remote areas such as the Orange Asal villages in Peninsular, Sabah and Sarawak, the coverage of the internet is limited. Some villages do not even have access to electricity, or it is very limited for nighttime usage. In order to help and provide guidance to the children, parents would need to be educated. One of the unintended consequences is the mental well-being of children during this crisis. As highlighted by Winthrop, there is a need to support children to ensure their well-being and reduce anxiety during a restless physically and emotionally. Therefore, it is important to ensure that there are strategies to help them cope with this "new normal" so that they could express their feelings on this new experience COVID-19 has shown a huge gap in digital divide among our students. In order to learn online via these platforms, a student would need to have access to the platform and guidance from parents.

\section{About the Study}

The whole system of education at all levels from school to university has been collapsed due to COVID-19 pandemic. It effects adversely to nearly 320 million students in India. They have transitioned to e-learning. There is a huge gap in digital divide among the students and parents. With huge regional, local and household disparities in access technology and internet, this transition has resurfaced long-standing issues of inequality that need to be 
addressed first to make the digitalization fruitful for all. Access to the online platform and appropriate guidance from parents to make use of the digital platform is very important for students to learn online. The present study is an attempt to assess the situation in providing education to school children in Odisha during pandemic. It would help us in decision-making to strengthen the online platform to provide quality education in one hand and also prepare a road map for effective and efficient implementation of New Education Policy 2020 with optimum utilization of technology. An attempt has been taken to collect both quantitative and qualitative data in the study, perceptions of various stakeholders (head teacher, teachers, students, parents and PRI members) on teaching-learning at a distance and the issues \& concerns of field functionaries in effective use of the technology, in the context of delivery of course content. It's essential to have a holistic overview of online teaching-learning activities during the lockdown for school children and establish a linkage between change in policy, administration and implementation to strengthen the ground with basic infrastructure, planning training, orientation and capacity building activities for teachers in the new paradigm of technology mediated world. Assessment and evaluation of ground realities is important for providing basic inputs to policy makers and educational administrators to have a sustainable system of technology mediated platform for facilitating teaching-learning at a distance, in the school education system of our country.

\section{Review of Related Literature}

Sudden imposition of lockdown due to COVID-19 pandemic and rapid transition of the whole teaching learning process from face-to-face regular classroom process to online remote learning process made us to face number of challenges, issues and constraints in real life situation. At the same time, it is (lockdown during COVID-19 pandemic all around) considered being full of opportunities in terms of wise use of ICTs in teaching learning process under the domain of online education. Issues like 'emergency remote teaching' (Bozkurt and Sharma 2020) or 'emergency eLearning' (Murphy 2020) and difficulties associated with poor online teaching infrastructure, lack of exposure and experience of teachers, information gap and the complex environment at home (Zhang et al. 2020) are some of the common issues before all stakeholders. At the same time, lack of mentoring and support (Judd et al. 2020) and issues pertaining to teachers' competencies in the use of digital instructional formats (Huber and Helm 2020) have also been identified. In the context of teacher education, how institutions and various stakeholders adapted to the new situation created by COVID-19 pandemic (Bao 2020; Flores and Gago 2020; Quezada, et al. 2020; Zhang et al. 2020) as well as training strategies and experiences of innovation (Ferdig et al. 2020) have been reported. For meaningful and productive online education, it is important to learn more about its potential and use, how the present context has forced all institutions to move to an online mode may provide a comprehensive understanding of adopted practices. It is necessary to ensure that these practices are effective and useful. This is, therefore, a crucial to study the present practices to have a road map with plan of action for future. The major emphasis was on online environments that enable teachers to focus on teaching and interact with students to provide them a variety of learning experiences in ONLINE mode. Therefore, issues of agency, responsibility, flexibility and choice are key elements as are 'careful planning, designing and implementation to create an effective learning ecology' (Bozkurt and Sharma 2020). As such, teaching and learning online entails a specific process which is visible in the roles, competencies and professional development approaches (Ní Shé et al. 2019) as well as in the curriculum, pedagogy, assessment and the nature of interaction among participants. It is, therefore, important to highlight how online education (technology mediated teaching-learning process) designed, developed and implemented for 
children at school level and to explore its implications, particularly in the context of rural and remote areas of Odisha to have sustainable quality school education system for all.

\section{Rational of the Study}

With imposition of lockdown nationally, all educational institutions in general and schools in particular are forced to make a choice of online mode for providing educational opportunities to students at their door steps. Though it was a burden on all stakeholders, but there were no other options before them. However, gradually teachers, students and parents used to adapt to these practices as a means of regular and routine system of education, in spite of all differences, issues and concerns of all kind. As it was not as an option for them, rather a compulsion and only option. Therefore, it was, necessary to ensure how feasible and effective these measures and practices are for the students? What extend the students benefit out of these practices? What comes in the way of their effective implementation? At the same time, it was felt essential to identify the issues and difficulties before various stakeholders (teachers, students and parents) in the whole process. This is; therefore, a study has been undertaken in the context of Odisha to obtain the ground realities to further strengthen future practices. The present study is an attempt finds the online strategies and interventions that works and does not work in various types of Odisha. At the same time to understand the characteristics, the processes, the outcomes and the implications of online interventions for making the teaching learning process qualitative meaningful. Thus, the study would provide how online education occurred in the context of school education in rural and remote areas of Odisha and how to make it more effective and efficient for the future with blended approach as a means of sustainable quality enhancement initiative in the state.

\section{Research Questions}

The findings of the study would answer to the following research questions:

1. In view of COVID-19 pandemic, what is the status of implementation of online mode of education for school children in Odisha?

2. What are the perceptions of various stakeholders (teachers, students and parents) associated with the transition of education from face-to-face classroom practices to online remote mode of teaching learning process at school level in Odisha?

3. What are the fundamental issues and challenges faced by the stakeholders in adapting to the online education during COVID-19 pandemic?

\section{Objectives}

The following objectives are set forth in the present study:

1. To find the overall status of online mode of teaching-learning adopted during COVID-19 pandemic in various schools.

2. To study the perceptions of various stakeholders (teachers, parents and students) on online education during COVID-19 pandemic.

3. To identify the issues and challenges faced by the stakeholders in adapting to the online education during COVID-19 pandemic.

\section{Methodology of the Study}

Method: Descriptive survey method was used in the present study. Descriptive research is used to describe characteristics of a population (stakeholders)/phenomenon being studied. It is meant to addresses the "what" question not answer questions about how/when/why the characteristics occurred. This method of study aims accurately and systematically to describe a population, situation or phenomenon and can use a wide variety of research methods to investigate one or more variables

Sample: The study was conducted in three rural districts such as Koraput, Kalahandi and Kondhamal and three coastal districts such as Ganjam, Khorda and Cuttack of Odisha. From each district 100 students (50 from secondary level, 30 from upper primary level and 20 from 
primary level), 50 parents (25 parents of the students' secondary level, 15 from upper primary and 10 primary), 50 teachers (25 teachers of secondary level, 15 from upper primary and 10 from primary level), and 20 head teachers (10 from secondary schools, 5 from upper primary and 5 from primary level) identified randomly for the present study. Accordingly, 600 students (300 from secondary level, 180 from upper primary level and 120 from primary level), 300 parents (150 parents of the students' secondary level, 90 from upper primary and 60 primary), 50 teachers (150 teachers of secondary level, 90 from upper primary and 60 from primary level), 120 head teachers (60 from secondary schools, 30 from upper primary and 30 from primary level) and identified randomly for the present study from six districts of Odisha.

Sampling Strategy: Multistage stratified random sampling technique was adopted for selection of sample of the stud. Multistage sampling divides large populations into stages to make the sampling process more practical. A combination of stratified sampling or cluster sampling and simple random sampling is usually used for the convenience of the study.

Tools \& Techniques: Separate Questionnaire (Google Forms) for each stakeholder (Student, Teachers, Head Teachers, Parents and PRI Members) was prepared for collection of relevant information. Also, telephonic interviews were conducted with 360 stakeholders (60 from each district@20students, 10 teachers, 10 Head teachers, 10 parents and 10 PRI members) on various aspects of teaching learning process, issues, and concerns to get their feedback. A focus group discussion was made through virtual mode with each kind stakeholder separately to have a direct interaction with the stakeholders to assess the situation with more clarity and with better understanding.

Statistical Technique: Mean and percentage were used to have an analysis of the whole situation as per the objectives pertaining to various aspects of technology mediated interventions made during the critical situation of COVID-19 all around.

\section{Analysis and Interpretation}

A comprehensive analysis helps to understand the data by describing general trends in the data and pointing out differences and similarities among data points. Interpretation is a means to relate data to the objectives of the study. Analysis and interpretation address what do the data say about your sample of the study? It's an attempt to address the research questions comprehensively. In the present study the analysis and interpretation have been made in three different heads in view of types of stakeholders associated with the study.

\section{A. Perspectives of Head Teachers and Teachers of Various Schools}

i) Management of available resources and monitoring: With the lockdown and abrupt closing of schools, colleges, universities and all other educational institutions there was a feeling of fear and uncertainty among all stakeholders at all levels about the education of their words. It was a great challenge for educational administrators, policy makers and all other stakeholders associated with education of children at different levels. There was no planning, no preparation, no resources, no training and no movement all around. At the same time there was no other alternative, other than to switch over to virtual (online) mode from face-to-face classroom situation. About 43.6 percent head teachers of various schools viewed that they switched to virtual mode to continue their teaching-learning process and about 18.2 percent viewed that they made some arrangement to provide intervention to students of selected classes only. Whereas 38.2 percent head teachers viewed that no such shift to online mode has been made, often inputs are provided to students through telephonic conversation and one to one interaction through home-based care to some extent. With the 
beginning of lockdown (third week of March 2020) till one month (about the end of April 2020), around 97.2 percent of head teachers (out of the whole who could switch to online mode) did not provide services of any kind due to unavailability of resources, lack of proper directions, guidelines from their department and lack of knowledge and understanding about the new mode (online) of education. Privately managed school, their administration, their head teachers (principals) and teachers were found to be at one step ahead in this aspect, pertaining to mutual sharing of information and mutual learning about the ways and means teaching/learning etc.

School fee was not an area of concerns for the parents of children studying in Govt. Schools. However, it's a big concern for the parents of children of private schools. In one way there is closure of schools, no classless, no activities \& other interventions, no plan/schedule for the alternative mode. On the other side there are huge monthly fees. Also, some of the private schools increased their fee in the new session. The time is challenging for the school administration to plan, generate resources and implement, for the teachers to acquire new skills of teaching learning to reach to their children. The major issue in private schools is providing salary to school staff. About 89.7 percent head teachers expressed that it's difficult to manage the salary of school staff, as they are all used to meet out of the school fee only. Very few parents (less than 30 percent) made their payment towards the school fee. There is no other source of income and grants for the private schools to manage their expenses. It becomes increasingly difficult to meet the recurring expenses. However, they are all trying and taking steps to make some arrangements of resources, providing some sort of training to training to teachers and gradually managing the system for online classless with structured schedule for each class. However, the situations in the Government schools are quite different in real sense. There is hardly any means of synchronous online process/mode to deal with the children. There are many other conditions and factors which are in the way of planning, designing and implementation of online sessions in the context of Got schools as coming out during telephonic discussion and focus group interaction with various stakeholders. Some of the issues and concerns are genuine such as geographical conditions, financial conditions of parents, unavailability of resources at the schools etc, Besides, decision making at multiple levels, competencies of stakeholders, interest, motivation and enthusiasms etc also a major hurdle in the way of implementation and taking initiative with a new thought and new level.

About 53.8 percent head teachers of made provisions of technology mediated communication (discussion and interaction) with their teachers during the lockdown period. In case of private school, it was 74.6 percent and in case of Govt. School it was only 33 percent. This shows the extent of communication gap between the head teachers and teachers during the course of lockdown situation. Guidance and counseling to students and their parents on mental health and hygiene is considered to be very important and key factor to ensure sound mental health as the system, structure and interventions are all come to an end abruptly. There is no other means of guidance and services for the parents and their word about their education and to make them understand about their course of action. Only 7 percent head teachers viewed that they made some provision to communicate with their parents and students to provide feedback and guidance on sound mental health and hygiene. These aspects should have been given more emphasis and considered to be prerequisite for all school children, which was found almost neglected. The situation is very poor almost NIL so far as students and parents of Govt. schools are concerned. There are no specific guidelines and COVID-19 protocol for schools to prevent the spread of this novel corona virus. Only 27.4 percent head teachers pointed that they are aware of the general 
guidelines \& protocol released from Got of India and Got of Odisha to prevent the COVID-19. They are of the opinion that government should release specific guidelines for the schools indicating roles responsibilities and preventive measures to be taken at all level by all stakeholders. At the same time about 69.7 percent of head teachers viewed that network connectivity is a big issue in implementation of online sessions to provide academic support services to learners. Even teachers and parents are ready to spend on devices. However, the ultimate utility and its effectiveness depend on the connectivity. Therefore, the role of Govt. is very important inuring speed of connectivity at all locations. More than 86.8 percent of students and parents of rural and remote districts (particularly in Koraput, Kalahandi and Kondhamal districts) did not have smart phone to access the online sessions. This is reality and another major hurdle in implementation of online sessions in the context of Odisha.

Implementation of Online education requires specific set of skills and competencies in designing, development and implementation of course content. Teachers are to be trained and exposed in these areas. Management of face-to-face classroom is different and online classroom is different. This is clearly pointed by more than 91.3 percent of head teachers. They all require a different set of skills, training and orientation for making their classes effective and more efficient. They all agreed that COVID-19 taught them to make use of technology for the cause of teaching learning process and making their teaching learning more qualitative. The facilitates and exposure being provided to teachers in private schools by their management and the initiatives initiated for students of private schools should also be made at Govt. schools to address to the issues of inequality in school education.

\section{ii) Understanding obstructions, feasibility and comfort in imparting education online:}

Schools, colleges, universities and many other forms of educational institutions have faced numerous challenges during this critical situation of pandemic all around. More than 67 percent teachers of private school manage the situation gradually with more ease of adaptation to new form of teaching learning process with use of technology without even formal training and orientation. However, the situation in Government schools is very poor. Only 8 percent of the teachers viewed that they could manage the new form of teaching learning process using technology mediated interventions. The major causes as cited were non availability of devices (appropriate resources) and internet connection, lack of institutional approach and lack of motivation from the higher authorities. It is also found that more than 21.4 percent of teachers from Got schools did not give any response to this item. It's a fact that more than 90 percenter teachers from Govt. School have been struggling to cope up with the situation. Similar situation is found among teachers of private schools in rural/remote areas than that of the teachers from cities/towns. Training, orientation and capacity building is very important for effective and efficient use of technology in teaching learning process. It's found that very few teachers explore their own ways and means to learn and equip themselves to acquire the knowledge and skills in using technology during the COVID-19 pandemic. However, at some of the places they tried to manage the situation using some of the interventions through asynchronous mode without even direct interaction with students for months.

Content development (e-content) is very important for effective and efficient use of technology mediated interventions. It's an art to design and develop e-content and required specialized skills to develop through training and orientation. Such facilities and provisions are hardly made for school teachers at various levels. About 89 percent teachers from Govt. schools and 67.5 percent teachers from private schools viewed that its very time consuming and they required training and orientation to handle it. Very few teachers from private schools 
(about 9.82 percent) and government schools (7.1 percent) expressed their willingness to get involve in e-content development and their implementation through online classes and other means of technology mediated interventions. Institutional initiatives and organized efforts were not found in design and development of e-content and its implementation. Which is found to be a serious issue \& concern as far as quality of online teaching learning process is concerned. As success of online teaching and technology mediated teaching learning depends upon the success of team not on an individual. These aspects should be explained to teachers and the school administrators should internalize it to make use of it in the present context of teaching learning process. Availability of appropriate resources (devices) and sound internet connectivity is the central need for the success of online/technology mediated teaching learning process. At many of the Govt. schools (more than 77.4 percent) they are not available. However, in many of the private schools (more than 76.9 percent), though these resources are available, however, they are yet to be utilized optimally for teaching learning process. This shows that, in-service teacher education programmes need to be redesigned in the context of teaching learning through technology mediated interventions. This seems to be the new norms of teacher education with a paradigm shift in teaching learning process. Even, there should be programmes for trainers, master trainers and teacher educators to train them and to orient them in the context of online T-L process. The basics of four quadrant approach of online teaching learning process should be a part of teacher education programme (in service and pre service) at all levels.

Most of the teachers from Govt. schools (71.3 percent) and Private schools (94.3 percent) have smart phone with them for their day-to-day use. However, they had never utilized the smart phone for teaching learning process. Use of smart phone for online classes and for other means of teaching learning process is a new experience for all the teachers and a big surprised to them (teachers, head teachers and administrators as well) at the beginning, because, the situation of online classes were never thought of and never visualized as a normal routine practice for education of children at school level. Success of a new initiative depends on effective and efficient monitoring mechanism. Various aspects/dimensions of online education should also be thoroughly examined and monitored, as it is a new learning experience for all stakeholders. Participation of learners and their interaction is most important aspect of online teaching learning process. It was found that more than 90 percent students from private schools participated in online sessions. However, in case of Govt. schools it was found to less than 34 percent. This shows the level of preparedness of parents and teachers of Govt. schools for online education. This gap needs to be addressed to minimize the learning gap among the children. Non availability of resources is considered to the biggest hurdle for the students and parents of government schools. At the same time more than 42 percent of the parents expressed that there is lack of organizational planning and execution for development of awareness among the children and parents. This need to be addressed so as to have a workable plan of action keeping in view of issues, problem of the students and availability of resources around them. In Govt. schools, there were no online sessions (at synchronous mode) planned and organized by the teachers for routine teaching learning process. WhatsApp and SMS are the only the means of communication of teachers (more than 96 percent) with their students However, in case of private schools, WhatsApp and SMS are some the means to supplement the online sessions/interactions planned through open education resources. In private schools only 21.7 percent parents are concerned for the safety and security related measures as their Email and mobile number is shared during the course of online sessions. More than 43.3 percent parents are not aware about the issues related to security and safety measures. About 35 percent parents found to be casual towards these particular areas of safety and 
security as their priority was education of their children and they found no other alternatives for them.

\section{B. Perspectives of Students}

Students of Govt. schools (more than 86.5 percent) found to be deprived of the facilities of online education and failed to have direct discussion and interaction with their teachers for a long period. Even at many schools this situation still in place since March 2020. It's a serious issue for the students who would appear $10^{\text {th }}$ and $12^{\text {th }}$ board examinations in 2021 . Though there are provisions teaching and learning through television, 77.8 percent of the students viewed that they are not as per their syllabus and text book. Secondly, it requires pre broadcast and post broadcast discussion to help them to understand the concept and clear their queries. Continuity of the content and subject is very important, which was hardly found in programmes broadcasted in television and radio etc. as reported by more than 61.4 percent of students. Nearly 30 percent of the students did not give any response on such items. Only 11.2 percent students from Govt. schools reported that they watched the programmes broadcasted through television. Use of online interventions for delivery of course content is a new experience for all stakeholders (teachers, students as well as parents) at school level in general. About 69.2 percent of students of private schools and 88.3 percent from Govt. schools viewed that they prefer offline (face to face) class room process for teaching learning activities. Very few students (12.8 percent from private schools and 3.6 percent from Govt. schools) expressed their satisfaction on online system of education and stated that in view of the current situation they would prefer the online sessions as it gives variety of experiences. At the same time a group of students of about 18 percent from private schools and 8.1 percent from Govt. schools preferred integration of both online and offline mode for learning (blended mode). This shows that preferred mode of learning for the students was found to be face to face regular classroom situation. It may be due to lack of understanding of the users to use the technology mediated components effectively and lack of planning for delivery of online content and online resources as a means of teaching learning process. This shows that all teachers require specialized skillbased training to handle the online platform and the components to meet to the expectations of the learners and making the whole process more meaningful and productive. About 57.6 percent of students stated that their doubts and queries are taken up and addressed properly through online mode. At the same time about, 31.4 percent started that it's difficult to clear the doubts and queries online because of multiple problems/hindrances (loss of connectivity/ loss of audio/ loss of video etc) during the course of online sessions. There is no appropriate and systematic strategy/mechanism to raise the query and get their answers. Though there are various options available, but is not being utilized/ integrated by the teachers to address to individual queries through online sessions. About 11 percent students started that it's too difficult or even impossible to get clarity of the content in terms of clarification of doubts and queries. This shows that lot of efforts need to be made to equip the teachers to use facilities available to facilitate and promote one to one discussion and interactions with students during online sessions. The planning of sessions should be made more comprehensive in view of all components of teaching-learning to promote interaction of students with the teachers. This is important to establish the effectiveness of online sessions by enabling the students to develop a feel of classroom like situation.

About 48.3 percent students viewed that they are comfortable in making the basic necessary arrangements and preparedness for the online sessions. However, a large chunk of students about 50.7 percent viewed that they are in stress in terms of making the basic necessary arrangements and preparedness for the online sessions due to multiple reasons 
such as financial problems to arrange the resources, lack of knowledge and expertise to use the device/system, non availability of onsite support etc. It was found that more than 62.8 percent students from private schools are more concerned for exemption of school fees, purchase of books, cover up of syllabus etc. However, only 8.9 percent of students from Govt. Schools are concerned on these areas. Most of the students (about 79.2 percent) of government schools are more concerned for non availability of resources such as devices/system, internet connections and their use etc. Very few students from private schools (about 12.8 percent) are found to be concerned for these aspects. Only 39.7 percent students from private schools and 14.9 percent from Govt. schools are comfortable with the e-content. Majority of the students from each category of schools (51.4 percent from Govt. and 77.9 percent from private) stated that they need hard copies for preparation of content and for other purpose of evaluation.

\section{Perspectives of Parents}

Parents are important stakeholders in the whole teaching learning process. Particularly, during the time of pandemic, it's the parents who started learning first to help their children to learn out of the online interventions. While making an analysis it was found that parents of private schools are slightly in comfortable side than that of the parents of Govt. schools. It's because the initiatives and interventions of online services started early at the private schools and the Govt. schools started them at a later stage. On the other hand, issues of parents of both types of schools are found to be different. Parents of private schools are found to have more options to handle to their issues, queries and difficulties. However, in case of the parents of Govt. schools it very limited, due to lack of initiatives at the school level and inordinate delay in implementation at grass root level. About 89.3 percent patents of Govt. schools stated that teachers were also found to handicapped as because there were no clear directions and guidelines for them from the higher authorities. This was not an issue for the teachers of private schools as started by most of the parents (more than 90 percent) of private schools. About 77 percent of the parents of private schools are comfortable in terms of their understanding pertaining to online learning. However, this status is very low (about 21.3 percent) in case of parents of Govt. schools. Here comes the difference in providing adequate guidance and appropriate support services to their children by the parents for their education during COVID-19 pandemic all around. This is an important indicator and deciding factor to the extent of support services to children for their study and also increasing stress level of students.

Parents are of the opinion that students are comfortable and ready to adjust with the online mode and have an interest and willingness towards the new mode. But the major problem is providing those adequate resources, guidance and onsite support. It requires appropriate skills to handle the situation. Some of the problems are local, can be handled gradually by the parents. However, some of other problems are out of the hand of the parents, such as connectivity issue. About 61.9 percent parents of private schools have these issues. These issues are equally found with the parents of private schools in rural areas. So, what is required is development of base to strengthen the foundation with adequate resources and resolving the issues related to internet connectivity. More than half of the students in private schools are left out due to this particular issues. The issue is more prominent in rural areas and hilly areas. More than 80 percent parents in rural areas do not have the resources to avail online sessions. Very few, about 7 percent of parents of Govt. schools in rural areas have access to mobile device sessions. In case of parents of private schools in rural areas this situation is slightly better with availability of devices, with about 15 percent of parents. In rural areas about 83.2 percent parents of private schools started that 
there is financial burden on them to manage the resources for the online mode of education. In case of parents of private schools, the problem is remaining the same. However, the situation is slightly better i.e., about 72 percent parents of private school started that it's an additional burden for them to manage the resources for online mode of education. In case of urban areas, it is found that 48.9 parents of private school expressed that there is financial burden on the family to manage the resources. Only 27.8 percent parents of private schools in urban areas viewed that financial burden on family lightly increases due to online mode of education. The important aspect that is revealed from the study was that, parents (more than 64 percent) are agreed and convenience to spend a little out of their routine monthly family expenses on this (towards resources and internet connection) for the online mode of education. But they expect quality inputs and better academic services of all kind from the school management and expect involvement and participation of their children during the teaching learning process. About 71.2 percent parent viewed that it was just flow of information from one side (teachers) to another side (students) with some directions and assignments. Many other components of teaching learning process such as discussion, involvement, participation, interaction in real time is missing and neglected. It a serious concern leading to demoralize the students and students feel them isolated in the whole process. This shows the need of training, orientation and capacity building of teachers by the school administration in handling online resources for education and designing, development and implementation of e-text effectively and efficiently to make the online education more participatory and interactive.

\section{Overall Analysis}

On the basis of the findings of the present study it was found that a very small proportion of parents, about 23 percent ( 31 percent parents from private schools and only 15 percent from Govt. schools) are fully satisfied with the online education provided by the schools for their children. About 47 percent parents (52.1 percent from private schools and 41.9 percent from Govt. schools) are partially satisfied with the interventions provided by the schools during COVID-19 pandemic situation. About 19 percent parents (12 percent from private schools and 26 percent from Govt. schools) are not at all satisfied with the present form of online interventions. At the same time about 11 percent parents $(6$ percent from private schools and 16 percent from Govt. schools) did not respond to this particular item. From this it is concluded that a meticulous plan needs to be made to cater to the needs and expectations of all stakeholders for making the online education and various online interventions more meaningful and productive for the learners. While interacting with parents it was found that about 68.9 percent of parents (51.3 from private schools and 86.5 percent from Govt. schools) did not have any idea and clarity of blended approach and about 21.2 percent teachers did not respond to this aspect. This shows the level of knowledge and understanding among various stakeholders who are responsible and accountable for implementation of online interventions for learners at different levels in school education system.

Ministry of Education, Govt. of India took all initiatives to provide online services to students to enable them to continue their learning during the lockdown period. There are various learning platforms like SWAYAM, Diksha, SWAYAM Prabha, e-pathasala, NROER (National Repository of Open Educational Resources) etc designed and developed under GOI. Many of these platforms are run by the National Council of Education Research and Training (NCERT), NIOS, IGNOU and NITTT etc. and many other autonomous organizations of the Ministry of Education. In the present study an attempt was taken to access the level of awareness of various stakeholders about the initiatives of Govt. of India for facilitating online 
education for technology mediated quality interventions at school levels. It was found that only 41.3 percent (54.3 percent from private schools and 28.3 percent from Govt. schools) of headmasters of various schools are aware about SWAYAM portal of Govt. of India. SWAYAM Prabha channels are important in terms of reaching at the door steps of student's through DTH channels. About 38 percent of parents (51.6 percent from private schools and 24.4 percent from Govt. schools are aware about this online initiative of Govt. of India. Though the content delivered through this channel are very important and useful for the students, however, it was, found that there is limited awareness among the parents and many other stakeholders such as teachers and students in rural areas about this initiative and its use for school children and teachers. DIKSHA portal is an important online platform for training and orientation to school teachers. About 68.7 percent of the teachers (66.3 percent of teachers from private schools and 71.1 percent from Govt. schools) are aware about this portal, as this portal is being utilized by state Govt. for online training \& orientation of teachers from time to time. However, it is, yet to be utilized optimally in the state for teachers of all schools. Similarly, NISTHA is a capacity building programme for improving quality of school education through integrated teacher training. The ultimate objective is to competency enhancement of teachers and head teachers at elementary school level at state, district, block and cluster level. The finding of the study revealed that only 33.6 percent teachers from Govt. schools and 16.4 percent from private schools are aware about this particular initiative. At the same time, it was also found that teachers from rural areas (about 76.7 percent) are not aware of it and the matter was never been discussed during the training sessions being organized at cluster/block levels. This is truly a great set back to the important initiatives of Govt., particularly, the digital initiatives that are meant for grassroots level functionaries for quality improvement in school education.

\section{Discussions and Conclusion}

With sudden lockdown all around in March 2020, due to COVID-19 there were no other options before the educational institutions other than making a shift to remote learning through online mode from their routine classroom process. This was a great challenge for all at levels of education as the transition to online mode happened faster and there was no time to think and understand the dynamics of its utility. However, teachers in higher classes (IX, $\mathrm{X}, \mathrm{XI}$ and $\mathrm{XII}$ ) somehow managed as there was no option for them. But teachers of lower classes in general and teachers of lower classes of Govt. schools in particular struggled and started them at a very late. In private school this transition started at very fast in comparison to Govt. schools. It's true that this unexpected transition, from conventional face to face mode to a new online mode has put administrators, policy makers, teachers, students and parents at a great disadvantage and also at a great risk. School education suffered a lot as most of the schools has not been properly organized. The present paper assessed and described the issues and difficulties in remote learning in the wake of the COVID-19 pandemic. Like many other studies (Bao, 2020; and Henaku, 2020), the present study also found that poor internet connectivity as one of the main issues in remote learning. It is a major problem in rural areas of Odisha in terms of availability, speed telecommunication systems and ICT, not being properly developed (Aboagye eand stability as well. The findings of the studies (Coleman, 2011; and Henaku, 2020) corroborate the other result of this study in which inadequate learning resources are serious hurdles for making the online learning effective and efficient for the students. As a result, student failed to participate, involve and interact in the process of online teaching learning optimally. It has also come to the notice that financial burden on parents enhanced. This corresponds to the findings of Matswetu et al. (2013) in which financial problems faced by students in Zimbabwe in a distance learning set-up. The situation arises due to COVID-19 has made it more difficult for the parents who 
lost their jobs and are finding difficulty to get a job in hand to support their families on one hand and meet the expenses for education of their children on the other hand. The situation is worse for poor families in rural and remote places during the outbreak due to an unprecedented economic shutdown (Adle, 2020).

Students and parents raised the issues of electric power and its interruptions during online learning situation. It's an inevitable problem in virtual classroom set-ups (Castillo, 2020). Students located in rural, remote and hilly areas find it not only difficult but also impossible to stay connected online due to lack electricity and also due to poor internet connectivity. Issues of design, development and implementation of e-content come next to it, which are also major constraints of learning and issues before the teachers and the head teachers. In the name of online mode of learning, almost all teachers use mere text books as "learning content", meant for regular classroom situation. This shows lack of understanding, experience and lack of training \& exposure of teachers in remote learning (Chen et al., 2020) situation. Therefore, It's high time to train, orient the teachers to produce appropriate supplementary materials for online learning of students (Burgess \& Sievertsen, 2020). At the same time, it has come to the notice that teachers simply assign more and more assignments/questions to student (in the process of online learning) in each and every subject. So, it leads to develop more stress and anxiety in students. They find no discussion, involvement, participation in the process of online mode. Similar findings were obtained in the study of Sarvestani et al., (2019) where students voiced about the extensive and the large number of modules that they need to answer, as a part of online teaching learning process.

Students are having a hard time coping with online learning situation because of the poor communication between them. It effects students' motivation and their interest towards learning at a distance. Appropriate learning environment is very important for students to ensure their active participation in teaching learning process. This is also equally required in online mode. The sudden shift to online mode has hardly considered this aspect which ultimately affects the motivation, interest and also the performance of students. It's also a fact that schedule of online learning hardly considers general home responsibilities of students. This may not be an issue in metros and cities. However, this is one of the major issues in remote and rural areas because children used to engage and participate in routine household activities. Students' engagement in household responsibilities negatively affects their academic achievement (Poncian, 2017; and Amali, Bello \& Adeoye, 2018). Students spend almost the whole day for online classes and answering assignments and activities, thus giving them less time or no time to engage in physical activities, so experience strains (Sundarasen et al., 2020) of engaging about 6-8 hours/day in online sessions.

On the matter related to selection of subjects covered, almost all schools focused merely on core subjects (Science, Mathematics \& English) in online mode. Co-scholastic activities which are very important for all round development and integrated development are essential for socialization of children are worst effected during COVID-19 with implementation of online mode of education. It's found that many teachers (most of the teachers from Govt. schools) are struggling with real-time interaction with students in online mode. This may be due to lack of exposure and proper training on online interventions. This is the learning point for administrators and policy makers to make a shift in teachers training programme for future. It's essential to equip the teachers with knowledge and competencies to make use of online interventions effective and efficient not just an alternative to face-toface mode of teaching learning process but for integration with conventional face to face 
mode of teaching learning. Majority of the students and parents preferred conventional mode of learning through face-to-face mode over the online mode. Implementation of blended mode is the need of an hour. So, there should be organization of awareness programmes for parents and workshops for teachers at different levels for effective and efficient use of online mode of education and help them to appreciate the interventions of online mode.

Assessment is an important aspect of the whole teaching learning process. How best online tool and techniques of evaluation can be used by the teachers (for formative and summative evaluation) is an important point. Formative assessments are essential to assess the effectiveness of our teaching strategies, plan for future teaching-learning activities, to keep track of individual learner's progress, and to provide students with useful feedback for improvement. Google Forms can be use for summative assessment as they provide variety of questions and design concept-appropriate questions. Even teacher can use images, graphs, audios, and videos from YouTube, and design questions around these media. This would help teachers to assess and evaluate learners' understanding of students in the ways that were not possible with conventional mode of assessment and evaluation. Online tools along with Google's Classroom app could help teachers to streamline and automate much of administrative work, so that teachers can concentrate and focus on design, development and implementation of online tools for their classroom process.

Development of a good online support system with effective network with all educational institutions for mutual support is essential for quality enhancement and addressing to the issues of inequality. Teachers should learn to transform the difficulties and challenges into opportunities for their personal and professional growth. It is essential for effective and efficient use of online education in the context of our system of education. There should be a common platform where teachers can discuss and interact to resolve their queries and address the challenges they face. At this point of time, it's not important to complete the syllabus that had been planned at the beginning of the academic year. It's important to learn and comfortable with new tools and methods require for learning at a distance. Varieties of online activities should be planned during the course of online deliberations. This is a means to alleviate emotional and mental stress of students and maintain a positive outlook. Teachers require technical support and assistance to make their teaching learning process meaningful and productive in the new mode of imparting education. Success of online education is a team work with equal responsibilities and accountabilities on all stakeholders such as school management, head teacher, teachers, students and also parents.

\section{References}

1. Adle, C. (2020). COVID-19 and the Poverty Pandemic. Retrieved from https://philippines.oxfam.org/latest/blogs/covid-19-and-poverty-pandemic

2. Amali, l., et.al. (2018). Influence of domestic works on female students' academic performance in upper-basic schools in Kwara State, Nigeria. Journal of Education in Developing Areas, 26(1), 196-202. https://journalsplace.org/index.php/JEDA/article/view/44

3. Bao, W. (2020). COVID-19 and online teaching in higher education: A case study of Peking University. Human Behavior and Emerging Technologies, 2(2), 113-115. https://doi.org/10.1002/hbe2.191

4. Bozkurt, A. and Sharma, R. C. (2020). "Emergency Remote Teaching in a Time of Global Crisis Due to CoronaVirus Pandemic." Asian Journal of Distance Education 15 (1): i-vi. Accessed 24 July 2020. http://asianjde.org/ojs/index.php/AsianJDE/article/view/447

5. Burgess, S. and Sievertsen, H. H. (2020). Schools, skills, and learning: The impact of COVID-19 on education. https://voxeu.org/article/impact-covid-19-education

6. Castillo, J. (2020). Distance learning? Don't Take Power Availability for Granted. Retrieved from https://mb.com.ph/2020/09/25/distance-learning-dont-take-power-availability-for-granted/ 
7. Chen, T. and et. al. (2020). Analysis of user satisfaction with online education platforms in China during the COVID-19 pandemic. Healthcare, 8(3), 1-26. https://doi.org/10.3390 /healthcare8030200

8. Coleman, R. K. N. (2011). Assessing the Adoption of e-Learning in Ghanaian Universities: Case of some Ghanaian Universities. Retrieved from http://tu.divaportal.org/ smash/get/diva2: 1018665/FULLTEXT03.pdf

9. Ferdig, R. E. , et.al. (2020). Teaching, Technology, and Teacher Education during the COVID-19 Pandemic: Stories from the Field. Association for the Advancement of Computing in Education (AACE). Accessed 15 June 2020. https://www.learntechlib.org/p/216903/

10. Flores, M. A. and Gago, M. (2020). "Teacher Education in Times of COVID-19 Pandemic in Portugal: National, Institutional and Pedagogical Responses." Journal of Education for Teaching , Advance online publication. doi:10.1080/02607476.2020.1799709.

11. Henaku, E. A. (2020). COVID-19 online learning experience of college students: The case of Ghana. International Journal of Multidisciplinary Sciences and Advanced Technology, 1(2), 54-62. https://www.researchgate.net/publication/342586709

12. Huber, S. G. and Helm, C. (2020). "COVID-19 and Schooling: Evaluation, Assessment and Accountability in Times of Crises-reacting Quickly to Explore Key Issues for Policy, Practice and Research with the School Barometer." Educational Assessment, Evaluation and Accountability 32: 237-270. doi:10.1007/s11092-020-09322-y.

13. Judd, J. and et. al. (2020). "This is Not Teaching": The Effects of COVID-19 on Teachers . Accessed 25 July 2020. https://www.socialpublishersfoundation.org/knowledge_base/this-is-notteaching-the-effects-of-covid-19-on-teachers/

14. Matswetu, V. S. and et. al. (2020). Science student teachers' challenges and coping strategies in an open and distance learning environment in Zimbabwe. Makarere Journal of Higher Education, 4(2), 125-137. https://doi.org/10.4314/majohe.v4i2.1

15. Murphy, M. P. A. (2020). "COVID-19 and Emergency eLearning: Consequences of the Securitization of Higher Education for Post-pandemic Pedagogy." Contemporary Security Policy 41 (3): 492-505. doi:10.1080/13523260.2020.1761749.

16. Ní Shé, C. and et. al (2019). "Teaching Online Is Different: Critical Perspectives from the Literature." Project Report . Dublin: Dublin City University. doi:10.5281/zenodo.3479402.

17. Poncian, P. (2017). The impact of home environment on students' academic achievement in Tanzanian secondary schools: A case of Geita Town Council. Retrieved from http://hdl.handle.net/20.500.12661/480

18. Quezada, R. L. and et. al. (2020). "From Bricks and Mortar to Remote Teaching: A Teacher Education Programme's Response to COVID-19." Journal of Education for Teaching , Advance online publication. doi:10.1080/02607476.2020.1801330.

19. Sarvestani, M. S. and et.al. (2019). Students' experiences of e-Learning challenges: A phenomenological study. Interdisciplinary Journal of Virtual Learning in Medical Sciences, 10(3), 1-10. https://doi.org/10.30476/lJVLMS.2019.45841

20. Sundarasen, S. and et. al. (2020). Psychological impact of COVID-19 and lockdown among university students in Malaysia: Implications and policy recommendations. International Journal of Environmental Research and Public Health, 17(17), 6206. https://doi.org/10.3390/ijerph17176206

21. Zhang, W. et. al. (2020). "Suspending Classes without Stopping Learning: China's Education Emergency Management Policy in the COVID-10 Outbreak." Journal of Risk and Financial Management 13 (58): 1-6. doi:10.3390/jrfm13030055. 